\title{
Long-term survival and quality of life in Jehovah's witnesses after cardiac surgery: a case control study
}

\author{
Pierre Wauthy $^{1 *}$ D, Charalampos Pierrakos ${ }^{2}$, Louis Chebli ${ }^{1}$ and Redente Tortora ${ }^{1}$
}

\begin{abstract}
Background: We previously analyzed morbidity and mortality in Jehovah's Witnesses patients after cardiac surgery compared to control population patients. Patients who were Jehovah's Witnesses were operated in accordance with their philosophical convictions and in respect of their refusal of transfusions. We propose to assess long-term survival and quality of life in the patients of this preliminary study.

Methods: We contacted 31 adult Jehovah's Witnesses patients who underwent heart surgery at the Brugmann hospital between 1991 and 2012 and compared them to a control population of 62 patients that had no transfusion restriction, and matched them for sex, age at the time of intervention and the type of surgery performed. We compared long-term quality of life in both populations through the MacNew software, a validated instrument to assess quality of life of patients with cardiovascular disease. The long-term survival of patients was analyzed by Kaplan Meier curves.
\end{abstract}

Results: Long-term quality of life and survival do not appear different between the two groups. Patient evaluation by MacNew software shows comparable physical $(p=0.54)$, emotional $(p=0.12)$, social $(p=0.21)$ and global $(p=0.25)$ scores between the two populations. The analysis of the actuarial survival curves shows no differences in terms of long-term survival of these patients ( $p=0.37$ ).

Conclusions: Cardiac surgery in Jehovah's Witnesses can be performed with identical long-term quality of life and survival compared to surgery without blood transfusion restriction, if one follows rigorous blood conserving strategies.

Trial registration: NCT03348072. Retrospectively registered 16 November 2017.

Keywords: Bleeding, Blood transfusion, Cardiopulmonary bypass, Quality of life

\section{Background}

Cardiac surgery in Jehovah's Witnesses (JhW) represents a real challenge for surgeons, anesthesiologists and other medical teams. The use of advanced blood saving techniques makes it possible to propose to these patients cardiac procedures with a risk of morbidity and mortality revealed in case-control studies with almost the same number [1-4].

Nowadays, the use of a health-related quality of life questionnaire is very widely recommended to evaluate a medical practice [5]. The evaluation of the long-term

\footnotetext{
*Correspondence: pierre.wauthy@chu-brugmann.be

${ }^{1}$ Department of Cardiac Surgery, CHU Brugmann, Place A van Gehuchten,

1020 Brussels, Belgium

Full list of author information is available at the end of the article
}

health-related quality of life of patients who have received treatment has become the golden standard in evaluating the effectiveness of these treatments [5]. Patient quality of life assessment tools should be validated for the pathology investigated, in the language used to administer these questionnaires. The evaluation of the quality of life of patients who have undergone heart surgery can be performed using the MacNeW questionnaire [5] which has been validated in French [6].

The determinants of quality of life after cardiac surgery are poorly studied and poorly understood. Work analyzing these parameters in patients with cardiac surgery has evolved recently. It has been shown that the quality of life of patients after cardiac surgery has improved, including for older patients [7]. One of the

(c) The Author(s). 2019 Open Access This article is distributed under the terms of the Creative Commons Attribution 4.0 International License (http://creativecommons.org/licenses/by/4.0/), which permits unrestricted use, distribution, and 
pre-operative determinants of this improvement is the preoperative quality of life of the patients [8]. Recently, it has been reported that intensive care unit length of stay can significantly influence the quality of life of patients $[9,10]$.

We propose to evaluate long term survival and health-related quality of life of two cohorts of patients operated on the heart, one without transfusion restriction, the other refusing transfusions (Jehovah's Witnesses patients). These two cohorts of patients have already been the subject of a study evaluating early postoperative morbidity and mortality [Marinakis 2016].

\section{Methods}

The study was conducted in the Department of Cardiac Surgery at the University Hospital Brugmann in Brussels. The Hospital's Ethics Committee reviewed the study protocol and gave its agreement for the achievement of the study (CE 2016/23). The process of identifying JhW patients and controls has previously been detailed, as well as details of the anesthesiology and surgical management [2]. The control patients were matched for sex, age at time of surgery and the type of surgery performed. The control group was selected based on the type of surgical procedure to keep this variable constant, which can influence the comparison of outcomes.

The analysis of the quality of life in patients investigated was made with the MacNew: a heart disease Health-Related Quality of Life (HRQL) questionnaire. After patients gave their informed consent to study participation, the questionnaires were sent by post and self-administered by the patients. The results were collected over a telephone interview.

The evaluation is done by means of a questionnaire based on daily life during the 2 weeks prior and consists of 27 issues investigating the physical, emotional and social spheres of everyday life. Each domain is rated on a 7 points scale: 1 indicates poor HRQL and 7 excellent HRQL. Finally a global score, rated on a 7 points scale obtained by means of an average of each score, is determined. Mortality data and the quality of life questionnaire were collected by telephone interview. In the absence of response, the patient's physician was contacted to confirm his survival or death.

We performed an analysis of data using the Statistical Package for Social Science software v. 22 (SPSS Inc., Chicago, IL, USA) to compare JhW to control groups. Kolmogorov-Smirnov test was applied to verify the normality of the distribution of the continuous variables. Continuous variables were compared using Student $t$ test or Mann Whitney test as appropriate. Dichotomous variables were compared using the $\chi^{2}$ test. Survival was analyzed using the Kaplan Meier method and the data were compared with the log-rank test. Median follow up time was estimated as the time corresponding to the 50th percentile taken from reverse Kaplan Meier analysis. Statistical significance was defined as $p<0.05$.

\section{Results}

JhW group consists of 31 patients who underwent a variety of cardiac surgeries including elective and emergency surgery. The demographic characteristics of the patients are shown in Table 1. Surgical procedures were coronary artery bypass grafting in 55\%, valvular surgery in $29 \%$, combined coronary and valvular surgery in $10 \%$ and others in $6 \%$. We compared them to a control group of 62 patients. The demographic characteristics of Jehovah's Witnesses versus the controls are presented in Table 1. Patients were operated between January 1991 and December 2012. The minimum time from operation till questionnaire administration in both groups was 4 years (December 2016).

Among the 93 patients included in this study, 11 patients were lost to follow-up (all in the control group). Of the 82 remaining patients, 38 patients had died (14 in the JhW group and 24 in the control group $(p=0.99))$ and 44 survived. The median follow-up were 15.3 years (95\%CI $12-17)$ versus 15.9 years $(95 \%$ CI $14-17)$ in the $\mathrm{JhW}$ vs control group respectively. The actuarial survival curves of the two groups are completely superimposed: no significant difference in survival was demonstrated by analysis of Kaplan Meier curves (Fig. 1). Median estimated survival and survival at 0/5/10/15 and 20 years are expressed in Fig. 1. There was no difference between the two groups $(p=0.37)$.

The evaluation of quality of life was based on the 44 survivors (17 JhW and 27 controls). Three refused to answer the MacNew quiz (JhW 2 and 1 control) and 9 others were unable to respond due to dementia (JhW 1 and 8 control). Therefore, 32 patients in total participated in the evaluation of the quality of life with the MacNew (JhW 14 patients and 18 control). We compared between groups the delay between surgery and evaluation $(p=0.23)$ and age at the time of evaluation $(p=0.15)$. The MacNew scores were similar for both populations. Results are expressed in Fig. 2. The results are expressed in absolute value in Table 2.

\section{Discussion}

The assessment of HRQL is an increasingly important outcome in the management and care of cardiac patients [5]. Quality of life is a very broad concept, multidimensional and subjective which can be difficult to evaluate correctly. The MacNew questionnaire is a specific instrument for cardiovascular disease $[5,11]$. It takes into account physical, psychological, relational as well as more specific issues such as sexuality and self-image. $[5,11]$. Currently validated in 23 languages, the MacNew is a 
Table 1 Patients demographics

\begin{tabular}{|c|c|c|c|}
\hline & Jehovah's Witnesses $(n=31)$ & $\begin{array}{l}\text { Control Group } \\
(n=62)\end{array}$ & $p$ Value \\
\hline Age (years) & $62 \pm 15$ & $62 \pm 14$ & 0.873 \\
\hline $\begin{array}{l}\text { Women } \\
\text { BMI }\left(\mathrm{kg} / \mathrm{m}^{2}\right)\end{array}$ & $\begin{array}{l}10(32 \%) \\
27.4 \pm 4.3\end{array}$ & $\begin{array}{l}20(32 \%) \\
26.2 \pm 4.0\end{array}$ & $\begin{array}{l}1.000 \\
0.182\end{array}$ \\
\hline Euroscore II & $2.80 \pm 3.34$ & $2.38 \pm 2.20$ & 0.469 \\
\hline Preoperative Cockcroft's CC in $\mathrm{mL} / \mathrm{min}$ & $84 \pm 29$ & $82 \pm 27$ & 0.776 \\
\hline Renal insufficiency (Cockcroft's CC $<85 \mathrm{~mL} / \mathrm{min}$ ) & $16(52 \%)$ & $34(55 \%)$ & 0.769 \\
\hline Diabetes & $8(26 \%)$ & $15(24 \%)$ & 0.865 \\
\hline Recent smoker & $3(10 \%)$ & $17(27 \%)$ & 0.062 \\
\hline Hypertension & $18(58 \%)$ & $30(48 \%)$ & 0.379 \\
\hline Hypercholesterolemia & 19 (61\%) & $36(58 \%)$ & 0.765 \\
\hline Positive family history & $10(32 \%)$ & $18(29 \%)$ & 0.749 \\
\hline Cerebrovascular accident & $4(13 \%)$ & $5(9 \%)$ & 0.457 \\
\hline Peripheral vascular disease & $8(26 \%)$ & $6(10 \%)$ & 0.040 \\
\hline Previous myocardial infarction & $6(19 \%)$ & $11(18 \%)$ & 0.850 \\
\hline Recent myocardial infarction ( $<90$ days) & $3(10 \%)$ & $6(10 \%)$ & 1.000 \\
\hline COPD & $6(19 \%)$ & $6(10 \%)$ & 0.189 \\
\hline NYHA & & & 0.452 \\
\hline । & $6(19 \%)$ & $7(11 \%)$ & - \\
\hline$\|$ & $12(39 \%)$ & $21(34 \%)$ & - \\
\hline III & $10(32 \%)$ & $30(48 \%)$ & - \\
\hline IV & $3(10 \%)$ & $4(6 \%)$ & - \\
\hline Preoperative LVEF & $62 \pm 11$ & $59 \pm 14$ & 0.340 \\
\hline Preoperative AF & $5(16 \%)$ & $9(15 \%)$ & 0.838 \\
\hline Reoperation & $3(10 \%)$ & $8(13 \%)$ & 0.650 \\
\hline Urgent status & $7(23 \%)$ & $6(10 \%)$ & 0.091 \\
\hline
\end{tabular}

(BMI Body Mass Index, CC Creatinine Clearance, Recent smoker Current smoker or ex-smoker for less than 5 years, COPD Chronic Obstructive Pulmonary Disease, NYHA New York Heart Association score, AF Atrial Fibrillation, LVEF Left Ventricular Ejection Fraction)

reference tool in many studies. It intervenes in setting the therapeutic point of coronary heart disease (medical treatment, percutaneous angioplasty, bypass surgery, implantable defibrillator, pacemaker) in rehabilitation strategies and secondary prevention after heart failure, myocardial infarction, angina and cardiac surgery. Our evaluation method had to be adapted to French speaking patients, which is the case of MacNew [6]. This questionnaire was also validated after rehabilitation in cardiac surgery [12]. In the literature there are several discussions regarding the modality of administration of this type of questionnaire (interview, self-administration). Some studies conclude that different modes of administration of questionnaire do not lead to the same understanding of the issue and may affect the response provided. Therefore, care must be taken in interpreting the results in the administration of the questionnaire. We have been attentive to this aspect and have taken the necessary precautions so that the mode of administration of the questionnaire is identical for each patient of our study.
Many studies show the feasibility of cardiac surgery in JhW patients [13-16] but very few evaluate its long-term results. The only long-term outcome evaluated in a cohort of 322 patients over a 28-year period was based on patient survival and the occurrence of new cardiac events [3]. For the first time we report an evaluation of the quality of life of JhW patients after heart surgery and compare it to a control population. We lack the data for the 11 patients lost to follow-up. We could not assess the quality of life in 9 patients with dementia too advanced for them to respond to the interview. However, we believe that this condition has no connection with the refusal of transfusion during surgery: only one of them was a JhW. The quality of life assessed by the questionnaire was identical in the JhW population and the control population. The scores observed in both groups are close to the scores reported in the literature in patients after rehabilitation for treated coronary events [6].

There are many methods to analyze the long-term mortality of a population. The method used here is considered 


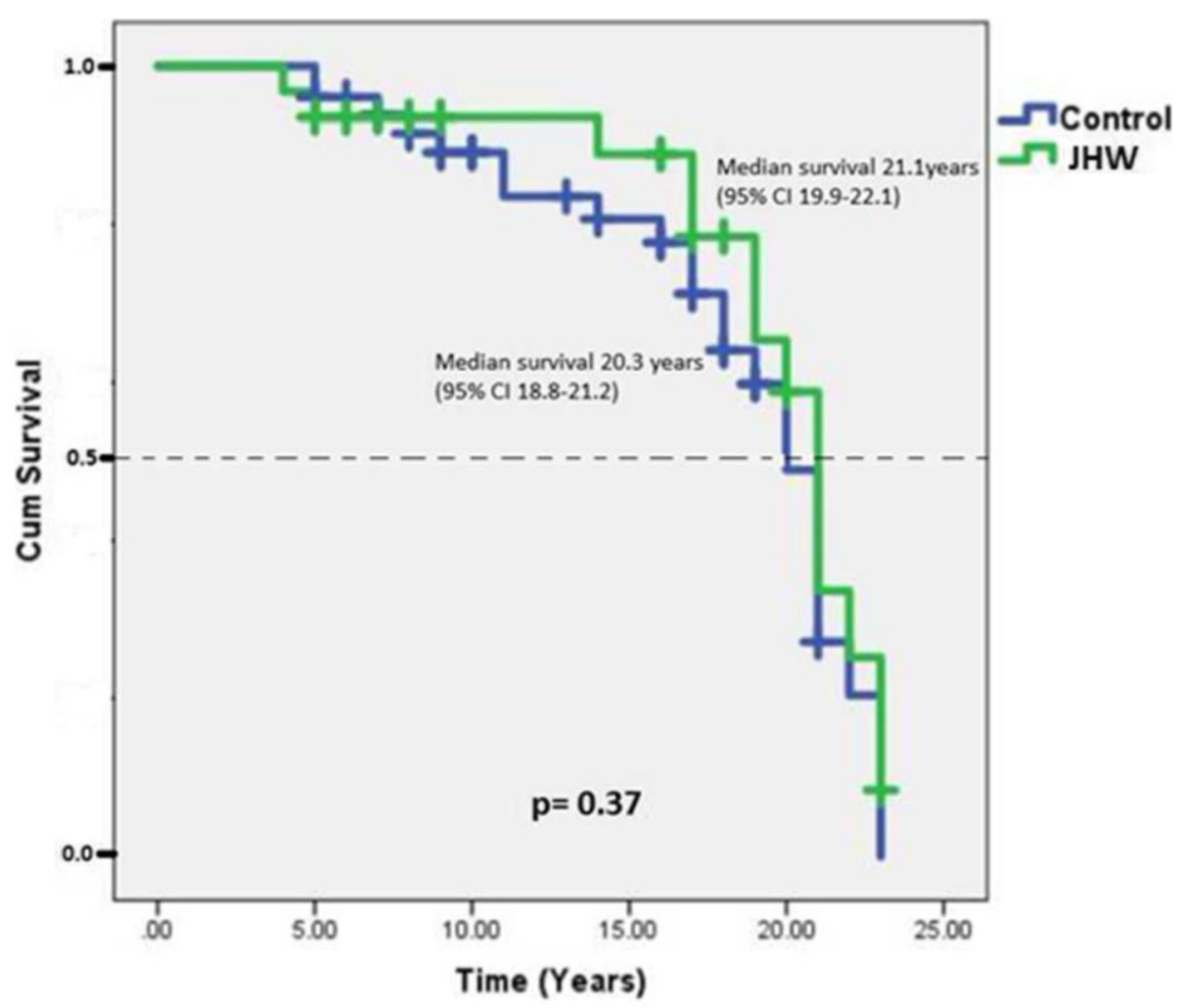

No at risk

Jehovah's witness

$\begin{array}{lllll}31 & 25 & 20 & 16 & 8\end{array}$

Control

$\begin{array}{lllll}51 & 45 & 32 & 22 & 10\end{array}$

Fig. 1 Kaplan Meier curves in the JhW (green) group and the control group (blue): $p=0.37$

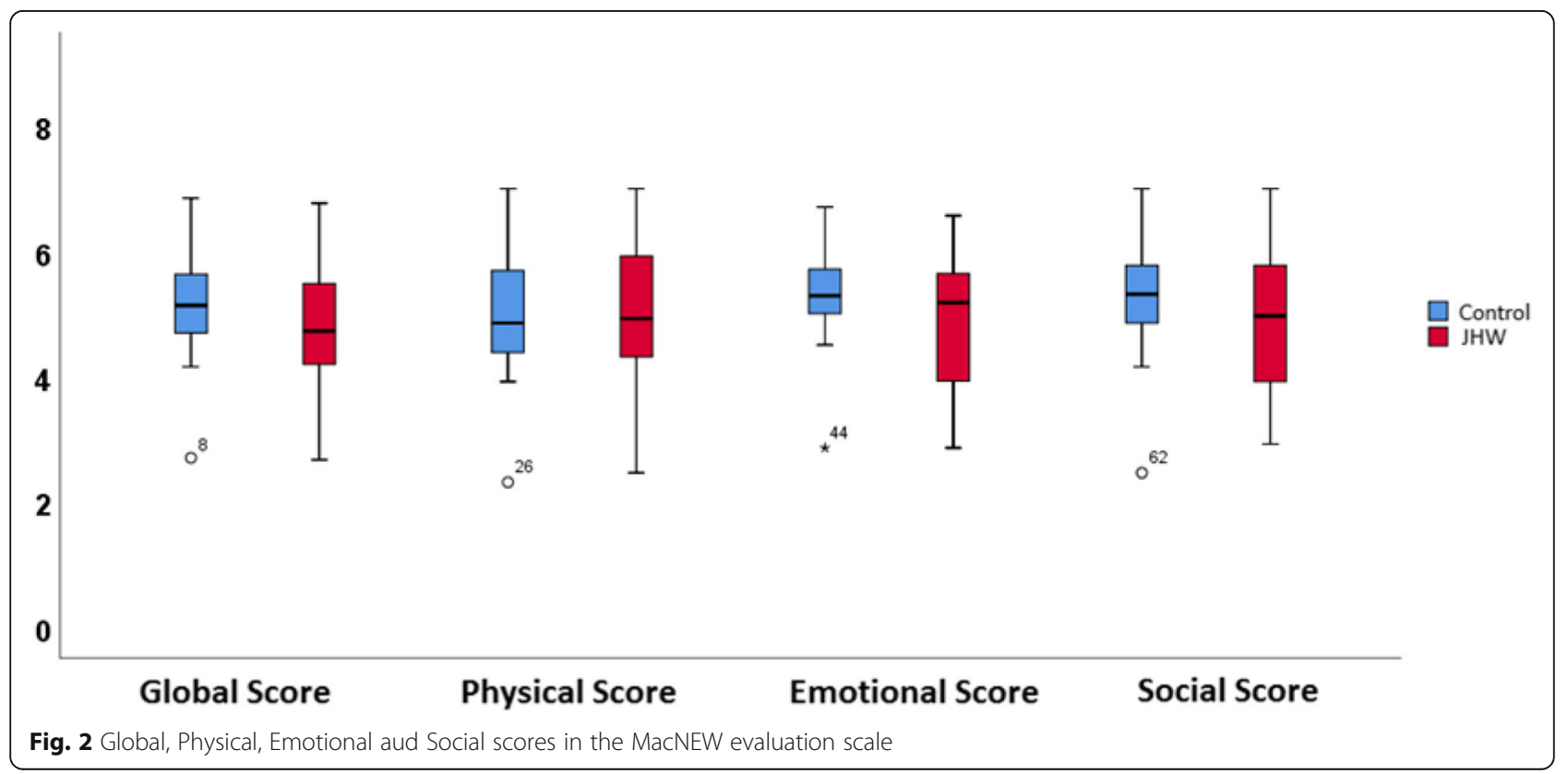


Table $2 \mathrm{MaCNew}^{\circledast}$ score

\begin{tabular}{llll}
\hline & JhW Group $(n=14)$ & Control Group $(n=18)$ & $p$ Value \\
\hline Physical score & $4.9 \pm 1.2$ & $5.2 \pm 1.1$ & 0.54 \\
Emotional score & $4.7 \pm 1.1$ & $5.3 \pm 0.9$ & 0.12 \\
Social score & $4.9 \pm 1.1$ & $5.4 \pm 1.1$ & 0.21 \\
Global score & $4.8 \pm 1.1$ & $5.2 \pm 1.1$ & 0.25 \\
\hline
\end{tabular}

JhW: Jehovah's Witness

as the most robust: a reversed Kaplan Meier survival curve. The obtained prediction curve extends to a post-operative period of about 25 years. In the current data, we have a postoperative follow-up period $\geq 20$ years in only 4 patients and between 10 and 20 years in 33 patients. The 45 remaining patients have a follow-up $\leq 10$ years. The actuarial survival curves of JhW patients and control patients are totally superimposable. The survival observed after 20 years is less than reported in the literature: $10 \%$ vs $32 \%$ [3]. This can be explained by the fact that JhW patients we studied differs significantly from other studies for surgeries performed. In our study, we find a wide variety of surgical procedures at high risk, including emergencies, reoperations and combinations of several techniques at the same operation. Anyway, our JhW population has the same life expectancy as our control population.

\section{Limitation of our study}

One must consider in the interpretation of the results that both groups are small and heterogeneous. This is particularly relevant for the assessment of the quality of life: only 14 and 18 patients responded to the MacNew questionnaire in the JhW and control group respectively. Future multi-institutional series are highly recommended to support our results and conclusions.

\section{Conclusions}

Overall long-term quality of life and survival in the JhW group were similar to the control group.

\section{Abbreviations}

HRQL: Health-related quality of life; JhW: Jehovah's witnesses; SPSS: Statistical package for the social sciences

\section{Acknowledgements}

Not applicable.

Funding

Not applicable.

Availability of data and materials

Please contact the corresponding author for data requests.

\section{Author's contribution}

RT have collected the follow-up data of this manuscript and partially drafted the manuscript. CP made the statistical analysis of the data. PW designed the study, drafted the manuscript and analysed the data. PW, LC, CP and RT corrected the draft of the manuscript. All the authors were involved in revising critically the paper and approved this final manuscript.

\section{Ethics approval and consent to participate}

This study was approved by the Brugmann University Hospital Institutional Review Board (Comité d'éthique hospitalier du Centre Hospitalier Universitaire Brugmann - OM 026) with the reference number CE 2016/23. The informed consent from each patient who agreed to participate in the study was obtained. Written informed consent was waived according to the procedure: the questionnaire was mailed to participants with an informed consent form. In case of agreement with the informed consent form, participants had to call the investigator to communicate the answers by telephone to the questions. The procedure has been validated by the ethics committee. The study is registered on clinicaltrials.gov with the reference number NCT03348072.

\section{Consent for publication}

Not applicable.

\section{Competing interests}

The authors declare that they have no competing interests.

\section{Publisher's Note}

Springer Nature remains neutral with regard to jurisdictional claims in published maps and institutional affiliations.

\section{Author details}

'Department of Cardiac Surgery, CHU Brugmann, Place A van Gehuchten, 1020 Brussels, Belgium. ${ }^{2}$ Intensive Care Unit, CHU Brugmann, Université Libre de Bruxelles, Brussels, Belgium.

Received: 30 May 2018 Accepted: 22 March 2019

Published online: 29 March 2019

\section{References}

1. Bhaskar B, Jack RK, Mullany D, Fraser J. Comparison of outcome in Jehovah's witness patients in cardiac surgery: an Australian experience. Heart Lung Circ. 2010;19(11):655-9.

2. Marinakis $S$, Van der Linden P, Tortora R, Massaut J, Pierrakos C, Wauthy P. Outcomes from cardiac surgery in Jehovah's witness patients: experience over twenty-one years. J Cardiothorac Surg. 2016;11(1):67.

3. Pattakos G, Koch CG, Brizzio ME, Batizy LH, Sabik JF 3rd, Blackstone EH, et al. Outcome of patients who refuse transfusion after cardiac surgery: a natural experiment with severe blood conservation. Arch Intern Med. 2012;172(5): $1154-60$.

4. Stamou SC, White T, Barnett S, Boyce SW, Corso PJ, Lefrak EA. Comparisons of cardiac surgery outcomes in Jehovah's versus non-Jehovah's witnesses. Am J Cardiol. 2006;98(9):1223-5.

5. Höfer S, Lim L, Guyatt G, Oldridge N. The MacNew heart disease healthrelated quality of life instrument: a summary. Health Qual Life Outcomes. 2004 Jan 8;2:3

6. Pavy B, lliou MC, Höfer S, Vergès-Patois $B$, Corone $S$, Aeberhard P, et al. Validation of the French version of the MacNew heart disease health-related quality of life questionnaire. Arch Cardiovasc Dis. 2015;108(2):107-17.

7. Gjeilo KH, Stenseth R, Wahba A, Lydersen S, Klepstad P. Long-term healthrelated quality of life and survival after cardiac surgery: a prospective study. J Thorac Cardiovasc Surg. 2018;156(6):2183-90.

8. Verwijmeren L, Noordzij PG, Daeter EJ, van Zaane B, Peelen LM, van Dongen EPA. Preoperative determinants of quality of life a year after coronary artery bypass grafting: a historical cohort study. J Cardiothorac Surg. 2018;13(1):118.

9. Barrie K, Cornick A, Debreuil S, Lee E, Hiebert BM, Manji RA, et al. Patients with a prolonged intensive care unit length of stay have decreased healthrelated quality of life after cardiac surgery. Semin Thorac Cardiovasc Surg. 2019 Spring;31(1):21-31.

10. Trivedi V, Bleeker H, Kantor N, Visintini S, Mclsaac DI, McDonald B. Survival, quality of life, and functional status following prolonged ICU stay in cardiac surgical patients: a systematic review. Crit Care Med. 2019;47(1):e52-63.

11. De Gucht V, Van Elderen T, van der Kamp L, Oldridge N. Quality of life after myocardial infarction: translation and validation of the MacNew questionnaire for a Dutch population. Qual Life Res. 2004;13(8):1483-8.

12. Eder B, Hofmann P, von Duvillard SP, Brandt D, Schmid JP, Pokan R, et al. Early 4-week cardiac rehabilitation exercise training in elderly patients after heart surgery. J Cardiopulm Rehabil Prev. 2010;30(2):85-92. 
13. Emmert MY, Salzberg SP, Theusinger OM, Felix C, Plass A, Hoerstrup SP, et al. How good patient blood management leads to excellent outcomes in Jehovah's witness patients undergoing cardiac surgery. Interact Cardiovasc Thorac Surg. 2011;12(2):183-8.

14. Jassar AS, Ford PA, Haber HL, Isidro A, Swain JD, Bavaria JE, et al. Cardiac surgery in Jehovah's witness patients: ten-year experience. Ann Thorac Surg. 2012;93(1):19-25

15. Marshall L, Krampl C, Vrtik M, Haluska B, Griffin R, Mundy J, et al. Short term outcomes after cardiac surgery in a Jehovah's witness population: an institutional experience. Heart Lung Circ. 2012;21(2):101-4.

16. Vaislic CD, Dalibon N, Ponzio O, Ba M, Jugan E, Lagneau F, et al. Outcomes in cardiac surgery in 500 consecutive Jehovah's witness patients: 21 year experience. J Cardiothorac Surg. 2012;27(7):95.

Ready to submit your research? Choose BMC and benefit from:

- fast, convenient online submission

- thorough peer review by experienced researchers in your field

- rapid publication on acceptance

- support for research data, including large and complex data types

- gold Open Access which fosters wider collaboration and increased citations

- maximum visibility for your research: over $100 \mathrm{M}$ website views per year

At BMC, research is always in progress.

Learn more biomedcentral.com/submissions 